\section{Synovial fluid ferritin in rheumatoid arthritis: an index or cause of inflammation?}

In many inflammatory disorders excess iron is found within reticuloendothelial cells. In patients with rheumatoid arthritis the synovial membrane contains an excess of iron (in the form of ferritin) concentrated within the cytoplasm and lysosomes of the type A reticuloendothelial cells. ${ }^{1}$ The concept that this iron may promote or worsen inflammation is not new. de Duve ${ }^{2}$ suggested that lysosomes containing phagocytosed material discharge their enzymes more readily than do normal lysosomes. Muirden ${ }^{1}$ suggested that incorporation of iron as ferritin in synovial cell lysosomes may facilitate enzyme release and promote tissue damage but failed to find a clear association between synovial membrane iron in rheumatoid patients and the degree of inflammation within the joints.

We found large quantities of ferritin within the synovial fluid of patients with rheumatoid arthritis but not in those with osteoarthritis. ${ }^{3}$ This ferritin is presumably derived from the synovial reticuloendothelial cells. To establish whether synovial fluid ferritin concentrations reflect local reticuloendothelial activity we correlated synovial fluid ferritin concentration with other indices of synovial inflammation. As intra-articular immune complexes are considered to be responsible for perpetuating chronic synovitis in patients with rheumatoid arthritis we also looked at their association with synovial fluid ferritin concentrations.

\section{Patients, methods, and results}

Synovial fluid was collected from 50 patients with rheumatoid arthritis with accompanying synovial effusion. A sample of the fluid was allowed to clot, centrifuged, and the ferritin concentration measured by radioimmunoassay (Gammadab ${ }^{125}$ I Ferritin Kit, Travenol Laboratories). Immune complexes were estimated by $1251 \mathrm{Clq}$ binding activity, and complement components (C3 and $\mathrm{C} 4)$ by radial immunodiffusion. The table shows the other laboratory indices of synovial inflammation measured. All data were non-parametric, and the relation between ferritin concentration and these indices was derived using Spearman's rank correlation coefficient (table).

Relation between synovial fuid ferritin concentrations and synovial fluid indices of disease activity in rheumatoid arthritis $(n=50)$

\begin{tabular}{lcc}
\hline \multicolumn{1}{c}{ Indices } & Correlation $(\mathrm{r})$ & Significance $(\mathrm{p})$ \\
\hline Rose-Waaler test & 0.41 & 0.01 \\
Absolute polymorph count & 0.30 & 0.05 \\
Synovial fluid glucose (fasting) & -0.30 & 0.05 \\
Ratio of serum to synovial fluid glucose & 0.60 & 0.001 \\
(fasting) & 0.57 & 0.001 \\
IgG & 0.37 & 0.01 \\
Total protein & 0.58 & 0.001 \\
Immune complexes & -0.57 & 0.001 \\
C3 (n=36) & -0.34 & 0.05 \\
C4 $(\mathrm{n}=36)$ & & \\
\hline
\end{tabular}

\section{Comment}

The observation that synovial fluid ferritin concentration correlates with other indices of inflammatory activity and immune complexes permits speculation about the nature of this association. In part the persistence of immune complexes within either serum or synovial fluid may be related to impaired function of the reticuloendothelial system, ${ }^{4}$ though the cause of this dysfunction is unknown. The conversion of ferrous to ferric iron during its incorporation into ferritin involves activation of molecular oxygen, and it has been suggested that when excess iron is stored oxidative-free radical reaction may promote tissue damage. ${ }^{5}$ The products of univalent oxygen reduction are all reactive substances in their search for stable electronic configurations and may exert a direct toxic effect on the reticuloendothelial cell.

We found a significant association between synovial fluid ferritin concentrations, synovial immune complexes, and other local indices of inflammatory activity in patients with rheumatoid arthritis. A common, and as yet unknown, factor is probably responsible for this association. The possibility that an excess of iron within the reticuloendothelial cell has a direct toxic effect, affecting its ability to clear immune complexes, should also be considered.

${ }^{1}$ Muirden KD. The anaemia of rheumatoid arthritis: the significance of iron deposits in the synovial membrane. Aust Ann Med 1970;2:97-104.

2 de Duve C. The lysosome concept. In: de Reuck AVS, Cameron MP, eds. Lysosomes. London: Churchill, 1963;1-35. (Ciba Foundation Symposium.)

${ }^{3}$ Blake DR, Bacon PA, Eastham EJ, Brigham K. Synovial fluid ferritin in rheumatoid arthritis. Br Med f 1980;281:715-6.

4 Williams BD, Lockwood CM, Pussell BA, Cotton C. Defective reticuloendothelial system function in rheumatoid arthritis. Lancet 1979;i: $1311-4$.

${ }^{5}$ Crichton RR. Interactions between iron metabolism and oxygen activation. In: Oxygen free radicals and tissue damage. Amsterdam: Excerpta Medica, 1979;57-76. (Ciba Foundation Symposium No 65.)

(Accepted 4 November 1980)

Royal National Hospital for Rheumatic Diseases, Bath BA1 1RL D R BLAKE, MRCP, senior registrar in rheumatology P A BACON, FRCP, consultant rheumatologist

\section{Variceal haemorrhage from a colostomy due to portal hypertension secondary to intrahepatic metastases from rectal carcinoma}

Haemorrhage from varices around an artificial intestinal stoma secondary to portal hypertension is well documented. Most commonly haemorrhage is from an ileostomy and attributable to portal hypertension caused by the cirrhosis associated with inflammatory bowel diseases such as ulcerative colitis ${ }^{12}{ }^{3}$ and Crohn's disease. ${ }^{4}$ Variceal haemorrhage from a colostomy has been less frequently reported. In one case of bleeding from a defunctioning transverse colostomy created to relieve obstruction of the sigmoid colon due to diverticular disease portal hypertension was attributable to coincidental alcoholic cirrhosis. $^{3}$ Secondary deposits in the liver are a rare cause of portal hypertension. Only one case of variceal bleeding from a colostomy due to portal hypertension secondary to intrahepatic metastases from a large-bowel carcinoma has been reported. ${ }^{5}$ I describe a further case.

\section{Case report}

The patient was a 52-year-old man who 18 months before had had a left iliac loop colostomy for an inoperable obstructing adenocarcinoma of the rectum; laparotomy had shown several metastases in the right lobe of the liver and almost complete replacement of the left lobe by secondary deposits. He had remained well until admission for severe haemorrhage from his colostomy, which had otherwise been functioning normally.

He was anaemic but not shocked. The abdomen was distended from ascites and showed pronounced hepatomegaly and dilated subcutaneous veins on the anterior wall, similar to the characteristic caput medusae. Around the colostomy, which had a bluish hue, were several dilated veins, one of which was identified as the source of the haemorrhage. The bleeding point was underrun with several sutures and 4 units of blood transfused. His general condition began to deteriorate, and two months later he presented with a further episode of acute variceal haemorrhage. Physical findings were as before, except that he was noticeably jaundiced. The bleeding point was again identified and underrun, adequate haemostasis being achieved. Blood transfusion was not required. Two days later he died from carcinomatosis; there had been no further haemorrhage.

\section{Comment}

Some case reports of stomal haemorrhage from mucocutaneous varices have confirmed the presence of portal hypertension mano- 
metrically. ${ }^{4}$ This was not feasible in this case but varices due to portal hypertension were assumed to be the cause from the characteristic appearance of the stoma ${ }^{5}$ and the presence of a caput medusae.

Various treatments have been advocated, but simple steps such as applying local pressure and underrunning of the bleeding points should be tried first. Any haemostatic defect associated with the liver disease should be corrected. The use of sclerosants such as sodium tetradecyl sulphate has also been suggested, ${ }^{5}$ and systemic infusion of vasopressin may prove useful. ${ }^{1}$ More radical measures such as amputation and refashioning of the stoma to effect venous disconnection, ${ }^{4}$ or portasystemic shunting by portacaval anastomosis, ${ }^{2}$ although useful in patients with cirrhosis due to inflammatory bowel disease, are not indicated in those with widespread metastatic disease.

I am grateful to Mr A G Dingley for permission to report this case, and to Professor Harold Ellis for help and encouragement.

${ }^{1}$ Hamlyn AN, Lunzer MR, Morris JS, Puritz H, Dick R. Portal hypertension with varices in unusual sites. Lancet 1974 ;ii:1531-4.

2 Cameron AD, Fone DJ. Portal hypertension and bleeding ileal varices after colectomy and ileostomy for chronic ulcerative colitis. Gut 1970 $11: 755-9$.

${ }^{3}$ Graeber GM, Ratner MH, Ackerman NB. Massive haemorrhage from ileostomy and colostomy stomas due to mucocutaneous varices in patients with coexisting cirrhosis. Surgery 1976;79:107-10.

${ }^{4}$ Eade MN, Williams JA, Cooke WT. Bleeding from an ileostomy caput medusae. Lancet 1969 ;ii:1166-8.

5 Finemore RG. Repeated haemorrhage from a terminal colostomy due to mucocutaneous varices with coexisting hepatic metastatic rectal adenocarcinoma: a case report. $B r \mathcal{F}$ Surg 1979;66:806.

(Accepted 4 November 1980)

Southend Hospital, Westcliff-on-Sea, Essex SSO ORY

R M WATKINS, FRCS, senior surgical house officer (now surgical registrar, Westminster Hospital, London SW1P 2AP)

\section{Lipoatrophy and monocomponent porcine insulin}

Lipoatrophy occurs in about $10 \%$ of patients receiving conventional insulin. ${ }^{1}$ Highly purified porcine insulin is not generally thought to cause this complication and is normally advocated for its treatment. ${ }^{1}$ We describe here, however, a case of lipoatrophy in a patient treated with monocomponent insulin.

\section{Case report}

A woman, now aged 60 , was first seen in June 1958 after glycosuria had been found on routine urine analysis. An oral glucose tolerance test confirmed the diagnosis of diabetes mellitus and she was treated with diet and chlorpropamide $(250 \mathrm{mg} /$ day). During November 1977 she was admitted with ketoacidosis precipitated by an upper respiratory tract infection and was treated with continuous intravenous infusion of monocomponent insulin

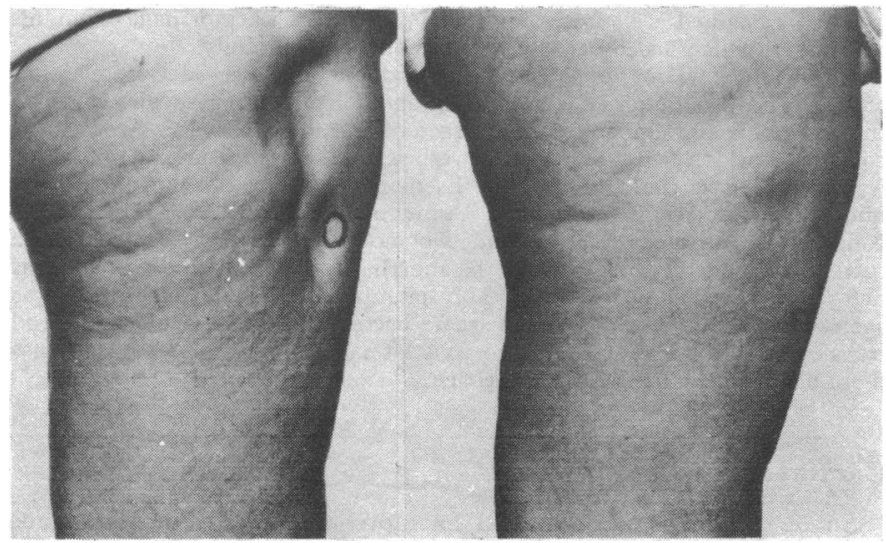

Lipoatrophic areas in leg before (left) and after (right) treatment.
(Actrapid MC). While in hospital she received one injection of Insulin Novo Rapitard (16 units subcutaneously). She was discharged taking insulin zinc suspension (Monotard MC) 36 units a day subcutaneously.

In November 1979 she developed lipoatrophy at injection sites on her thighs (figure) and upper arms. The hospital case notes and treatment sheets and her general practitioner's records yielded no evidence that she had received any insulins other than those mentioned. Biopsy specimens taken from the edge of lipoatrophic areas were snap-frozen in liquid nitrogen, and immunofluorescence analysis was performed. ${ }^{2}$ Mild speckling of $\mathrm{C} 3$ was seen at the dermal-epidermal junction and a mild diffuse increase in fibrin and fibrinogen in the upper dermis, but no IgM, IgG, C3, or Clq was deposited in the blood vessel walls. Serum insulin binding capacity, assayed by a second antibody coprecipitation assay specific for $\operatorname{IgG}$ antibody, ${ }^{3}$ was 15.9 $\mu \mathrm{g} / \mathrm{l}$. Serum insulin-specific IgE, measured by radioimmunoassay, was normal.

She was instructed to inject Actrapid MC (12 units) and Monotard MC (36 units) into the middle of the lipoatrophic areas. By July 1980 the affected areas had filled out (figure).

\section{Comment}

A similar case of insulin-induced lipoatrophy was reported by Hanai et al in Japan. ${ }^{4}$ Their patient had also been treated initially by diet and with a sulphonylurea and was later transferred to Monotard MC insulin. Unfortunately, the response to treatment was not mentioned. Our patient, however, responded well to monocomponent porcine insulin injected into the affected areas.

The cause of insulin-induced lipoatrophy is unknown. An immune pathogenesis in patients treated with conventional insulins was suggested by Reeves et al. ${ }^{5}$ They showed abnormal deposition of immunological components in the dermal blood vessels of all biopsy specimens taken from the edge of lipoatrophic sites. These were not presen in our patient. The findings of a mild speckling of $\mathrm{C} 3$ at the dermalepidermal junction and a mild diffuse increase in fibrin and fibrinogen in the upper dermis are non-specific and alone are insufficient to confirm the presence of an immunological reaction. The insulin binding capacity in this patient was $15.9 \mu \mathrm{g} / \mathrm{l}$; Reeves et al reported a range of $12 \cdot 7-58.8 \mu \mathrm{g} / \mathrm{l}$, with a mean of $33.1 \mu \mathrm{g} / 1$ in patients with lipoatrophy who had received conventional insulin and of less than $22.3 \mathrm{ug} / \mathrm{l}$ in patients who had received conventional insulins but did not have lipoatrophy. ${ }^{5}$ There was no evidence of a local immunological reaction in our patient.

We suggest that the pathogenesis of lipoatrophy in our patient, treated exclusively with monocomponent insulin, may differ from that in conventionally treated patients.

We thank Dr W G Reeves, Department of Immunology, University Hospital, Nottingham, for his reports on the immunofluorescence studies and assay of insulin binding capacity.

${ }^{1}$ Wright $\mathrm{AD}$, Walsh $\mathrm{CH}$, Fitzgerald MC, Malins JM. Very pure porcine insulin in clinical practice. $B r$ Med $\mathcal{F} 1979 ; \mathrm{i}: 25-7$.

${ }^{2}$ Marriott DW, Reeves WG. Immunofluorescence. In: Bancroft JD, Stevens A, eds. Theory and practice of histological techniques. Edinburgh: Churchill Livingstone, 1977:387-93.

3 Reeves WG, Kelly U. An immunochemical method for the quantitation of insulin antibodies. F Immunol Methods (in press).

${ }^{4}$ Hanai N, Kato N, Kawasaki M, et al. Lipoatrophy due to monocomponen insulin. Fournal of fapanese Diabetic Society 1976;19:427-8.

${ }^{5}$ Reeves WG, Allen BR, Tattersall RB. Insulin-induced lipoatrophy: evidence for an immune pathogenesis. $\mathrm{Br} M e d \mathcal{F} 1980 ; 280: 1500-3$.

(Accepted 14 November 1980)

Department of Medicine, University Hospital of Wales, Heath Park. Cardiff CF4 4XW

G R JONES, MRCP, research fellow

B STATHAM, MRCP, medical registrar

D R OWENS, MB, honorary clinical teacher

$M$ K JONES, MRCP, senior medical registrar

T M HAYES, FRCP, senior lecturer

\section{Correction}

Screening for congenital hypothyroidism in the Republic of Ireland

Several errors occurred in this paper by Sylvia Dockeray et al (6 December 1980, p 1519). Under Protocol in the materials and methods section 125 should read ${ }^{123} \mathrm{I}$; the dose of ${ }^{99} \mathrm{~m} \mathrm{Tc}$ is from 50 to $100 \mu \mathrm{Ci}$ and the irradiation dose to the thyroid is from 7 to $220 \mathrm{mR}$, while that to an infant's thyroid during anteroposterior chest radiography is $50 \mathrm{mR}$ or less. 